\title{
Utility of DMSP-SSM/I for integrated water vapour over the Indian seas
}

\author{
P N MAHAJAN \\ Indian Institute of Tropical Meteorology, Pune 411 008, India
}

\begin{abstract}
Recent algorithms for Special Sensor Microwave/Imager (DMSP-SSM/I) satellite data are used for estimating integrated water vapour over the Indian seas. Integrated water vapour obtained from these algorithms is compared with that derived from radiosonde observations at Minicoy and Port Blair islands. Algorithm-3 of Schlussel and Emery (1990) performed best. On the basis of this algorithm, distribution of integrated water vapour is determined during the monsoon depression (22nd-27th July, 1992) that formed over the Bay of Bengal.
\end{abstract}

\section{Introduction}

Information on large variations in atmospheric water vapour is of great importance for understanding the development of different atmospheric processes over the globe. Study of water vapour on synoptic and global scales for meteorological parameters is a difficult task due to the very small number of radiosonde stations, particularly over the global oceans.

In recent years, remote sensing of the atmospheric systems has been possible from a variety of microwave sensors. Most notable among these is the Special Sensor Microwave/Imager (SSM/I), a multichannel microwave radiometer with imaging capability, onboard American defense satellite series DMSP. In this study, DMSP-SSM/I data are used to study a monsoon system. Some of the algorithms developed in recent years have been examined and those found most useful over the Indian region have been used.

\section{Data and methodology}

Radiosonde data from Minicoy and Port Blair island stations are used for comparing in situ water vapour measurements with DMSP-SSM/I data. Radiosondes measure pressure, temperature and humidity at various levels in the atmosphere.
The measurements from the island stations of Minicoy and Port Blair are transmitted to the India Meteorological Department. Radiosondes do not report precipitable water directly, and hence need to be computed from temperature and relative humidity data. Making use of Tetens's formula (Tetens 1930) the vapour pressure of the air at each specific height is calculated as,

$$
\begin{aligned}
e s & =6.11 \times 10^{\frac{a T}{T+b}}, \\
e & =e s \times r h,
\end{aligned}
$$

where $e s$ and $e$ are the saturation and actual pressures respectively, $T$ is air temperature, $r h$ is relative humidity and $a$ and $b$ are constants. Mixing ratio, $r$ is computed as

$$
r=\varepsilon \frac{e}{p-e},
$$

where $p$ is the pressure in $\mathrm{hPa}$, and $\varepsilon$ is the ratio of molecular weights of water and dry air. Specific humidity $q$ is calculated as

$$
q=\frac{r}{1+r}
$$

Keywords. DMSP-SSM/I; integrated water vapour; IRS-P4. 

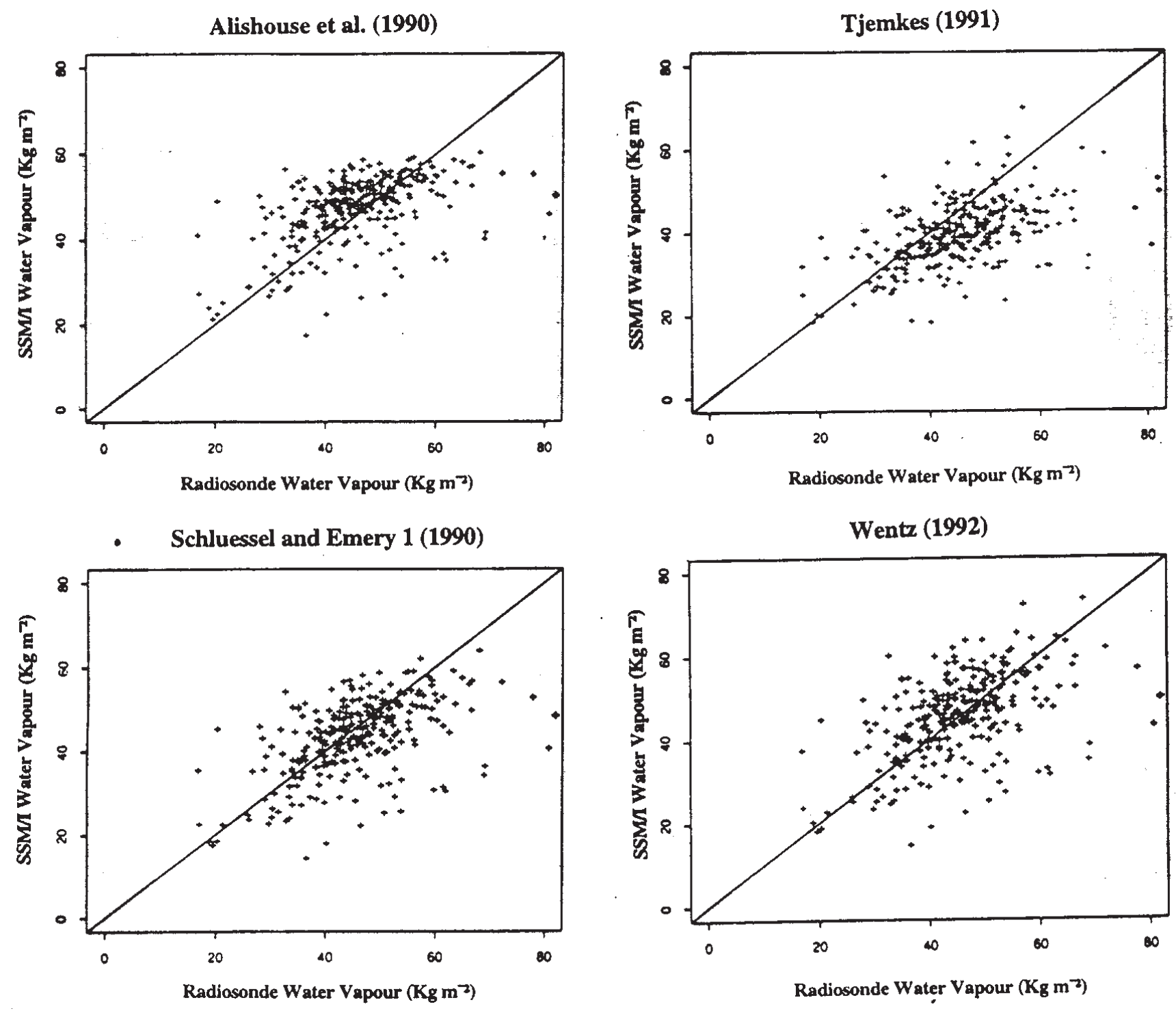

Figure 1. (Continued)

Table 1. Comparison of various algorithms for integrated water vapour.

\begin{tabular}{lrcrr}
\hline & $\begin{array}{c}\mathrm{rms} \text { error } \\
\left(\mathrm{Kg} \mathrm{m}^{-2}\right)\end{array}$ & $\begin{array}{c}\text { Correlation } \\
\text { coefficient } \\
(\mathrm{r})\end{array}$ & $\begin{array}{c}\text { Bias } \\
\left(\mathrm{Kgm}^{-2}\right)\end{array}$ & $\begin{array}{r}\text { Standard } \\
\text { deviation } \\
\left(\mathrm{Kgm}^{-2}\right)\end{array}$ \\
\hline Algorithm & 9.58 & 0.51 & 1.46 & 8.15 \\
Plishouse et al & 9.68 & 0.52 & 2.09 & 8.25 \\
Schluessel and Emery 1 & 9.85 & 0.51 & -2.17 & 9.02 \\
Schluessel and Emery 2 & 10.15 & 0.52 & -1.96 & 9.45 \\
Schluessel and Emery 3 & 9.57 & 0.56 & 0.16 & 8.37 \\
Lojous et al & 12.07 & 0.49 & 6.51 & 10.32 \\
Wentz & 10.05 & 0.51 & 0.08 & 10.19 \\
Tjemkes et al & 11.07 & 0.50 & -4.83 & 7.88 \\
\hline
\end{tabular}

$\mathrm{N}=317$ (Number of Minicoy and Port Blair radiosonde data match-ups that were coincidental with SSM/I overpasses). 

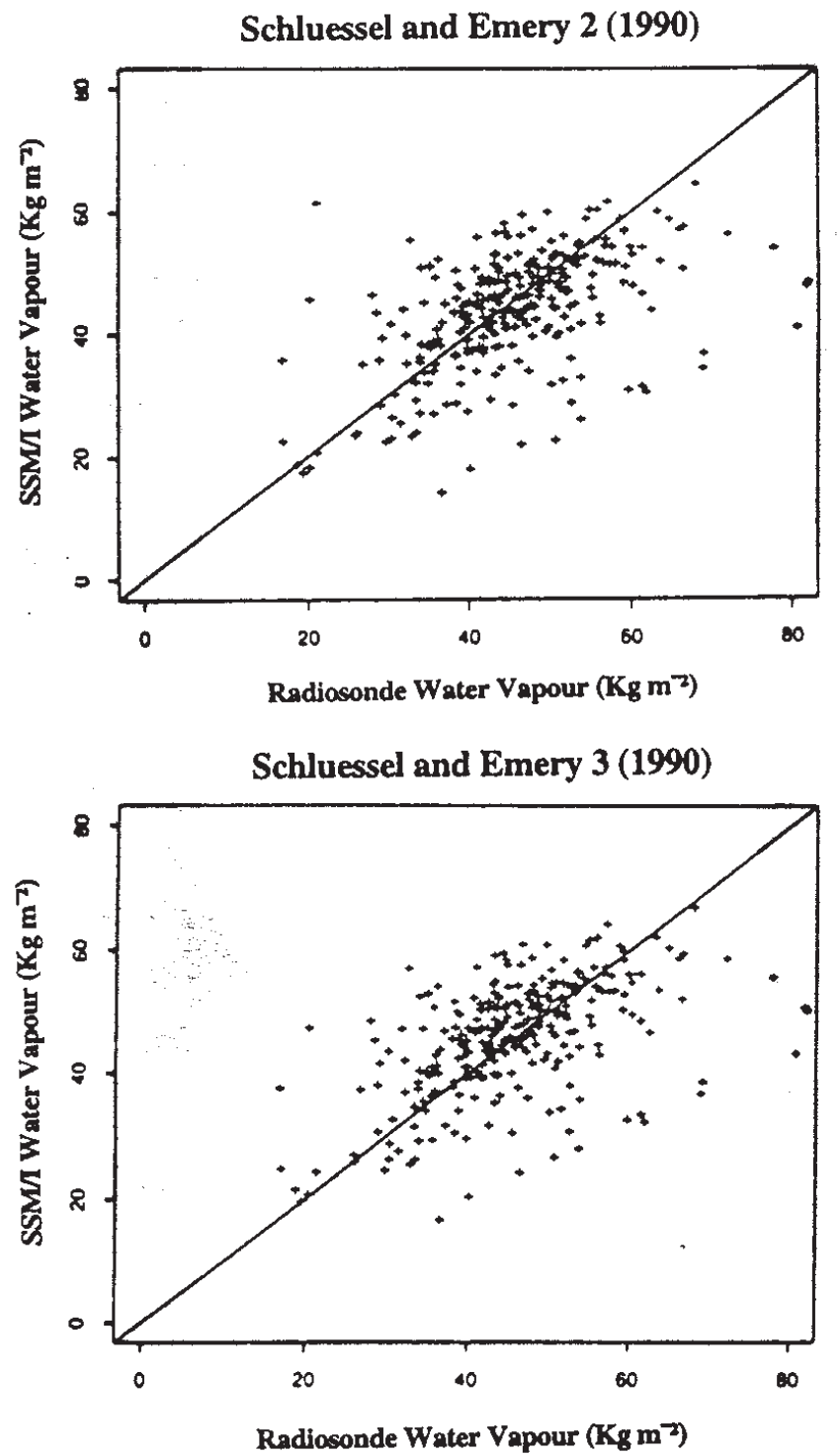

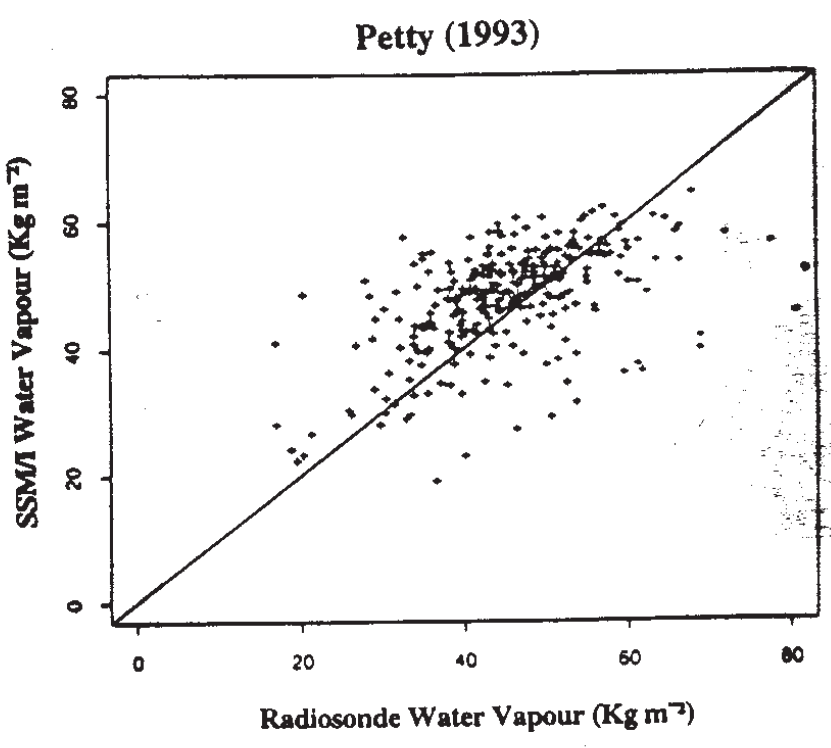

Lojous et al (1994)

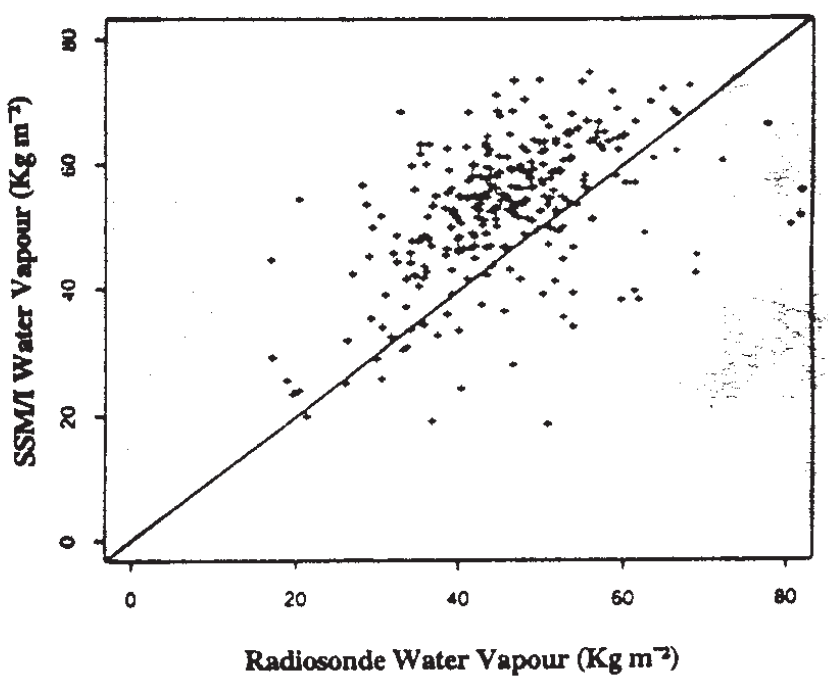

Figure 1. Scatter diagrams of integrated water vapour (WV) from Minicoy and Port Blair versus SSM/I (WV) for eight algorithms.

Precipitable water, $P W$, is computed by integrating $q$ for the whole atmospheric height:

$$
P W=\frac{1}{g} \int_{0}^{p_{s}} q \mathrm{~d} p .
$$

This integral is evaluated using the trapezoidal rule

$$
P W=\frac{1}{2 g} \sum_{i=1}^{n-1}\left(q_{i}+q_{i+1}\right)\left(p_{i}-p_{i+1}\right) .
$$

Though this expression has been extensively used, there is uncertainty about the upper limit of integration. Observations by radiosonde may reach up to $10 \mathrm{hPa}$. At this level the amount of water vapour is low. Relative humidity measurements derived from hygristor are not considered to be reliable at temperatures below $-40^{\circ} \mathrm{C}$. For such reasons, it is common practice to take the upper level to be $200 \mathrm{hPa}$ (Elliot and Gaffen 1991). We computed water vapour in three ways. The first is to cut off the integration at $200 \mathrm{hPa}$, the second at $-40^{\circ} \mathrm{C}$, and, the third is to integrate over the full height of radiosonde ascent. Annual distribution of radiosonde water vapour for each of these approaches show that the differences between the first two methods are very small. Hence the first two methods were used in subsequent analysis.

Integrated water vapour obtained from algorithms developed in recent years are compared with the integrated water vapour obtained from radiosonde data of Minicoy and Port Blair island stations. The algorithms examined are: (i) Alishouse et al 1990; (ii) Schluessel and Emery 1990; (iii) Tjemkes et al 1991; (iv) Wentz 1992; 

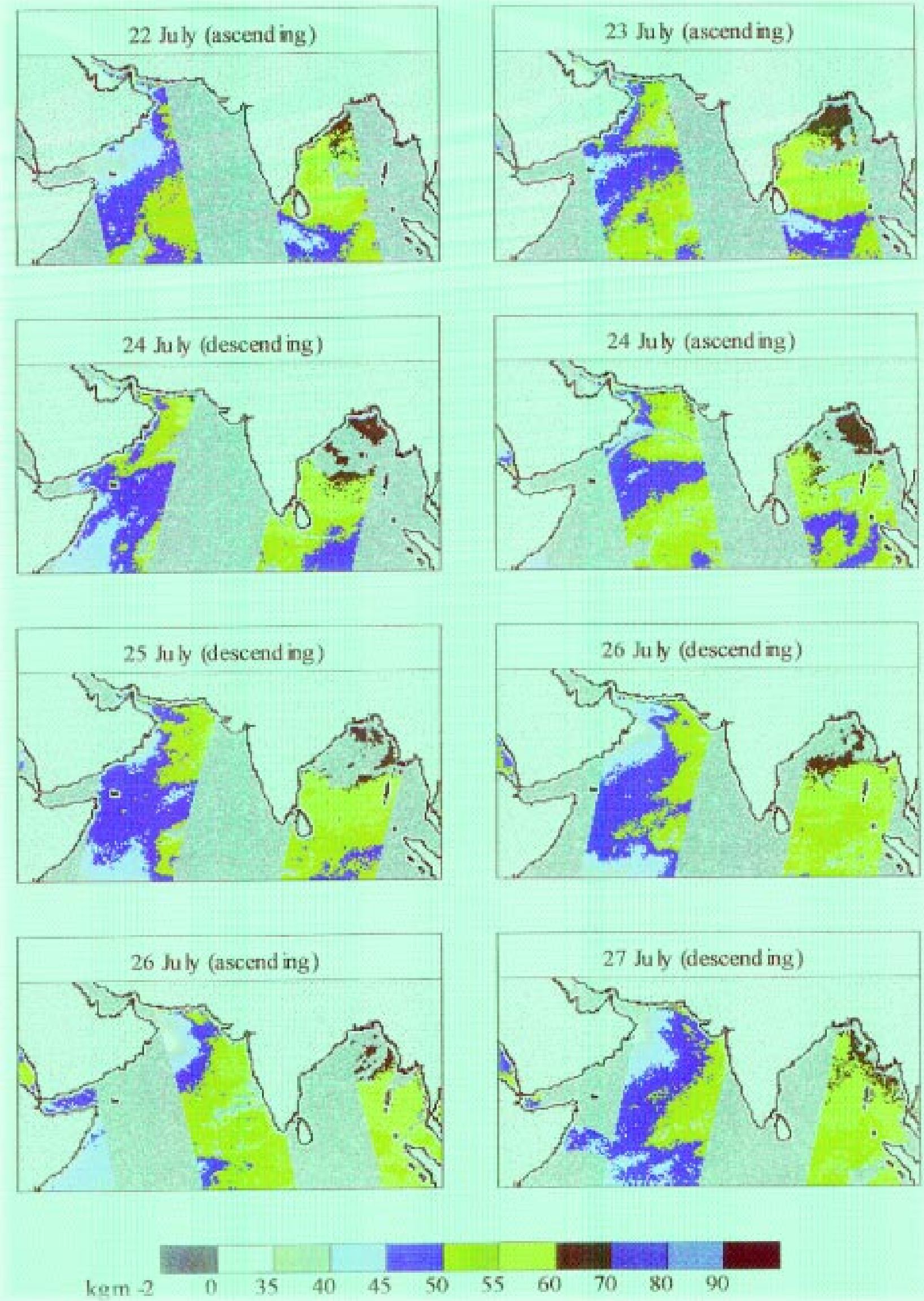

Figure 2. SSM/I derived integrated water vapour distribution during 22nd-27th July 1992. 
(v) Petty 1993 and (vi) Lojou et al 1994. Comparison between radiosonde water vapour versus $\mathrm{SSM} / \mathrm{I}$ water vapour for these eight algorithms is made in figure 1. Error statistics of these algorithms are given in table 1 .

From the scatter diagrams in figure 1 and from table 1 it is clear that the best match is obtained from algorithm-3 of Schluessel and Emery (1990). Hence this algorithm is used for the estimation of integrated water vapour. The algorithm is as follows:

$$
\begin{array}{rl}
W V=10.0 & *(23.82-4.059 * \ln (280-22 \mathrm{v}) \\
& +0.02451 *(\ln (280-22 v)-37 \mathrm{v}))
\end{array}
$$

where $22 \mathrm{v}$ and $37 \mathrm{v}$ are microwave brightness temperature used in $22.235 \mathrm{GHz}$ and $37 \mathrm{GHz}$ vertical polarisation.

\section{Results and discussion}

A depression formed over the Bay of Bengal during 22nd-27th July 1992. Figure 2 gives the distribution of integrated water vapour obtained from $\mathrm{SSM} / \mathrm{I}$ data during this period. Integrated water vapour values ranging from 45 to $70 \mathrm{Kgm}^{-2}$. The head Bay and the adjoining central Bay had maximum water vapour $\left(60-70 \mathrm{Kgm}^{-2}\right)$ throughout the period of study.

During the summer monsoon season, the genesis of monsoon disturbances is at least partly caused by transport of large amounts of moisture over the Arabian Sea and the Bay of Bengal. Information on the moisture fields over these areas plays an important role in understanding the dynamics of the monsoon systems. Most of the earlier studies are based on data from radiosonde stations over the oceans. Hence their horizontal distribution is not reliable. Satellite data make it feasible to study the distribution of moisture over large and remote oceanic areas because of their wide spatial and temporal coverage. In the present study, before the formation of monsoon depression, the oceanic area north of $8^{\circ} \mathrm{N}$ had water vapour $50-70 \mathrm{Kgm}^{-2}$ and south of $8^{\circ} \mathrm{N}$ had $45-55 \mathrm{Kgm}^{-2}$. With the forma- tion of low pressure system and its subsequent intensification into a depression, more moisture was brought over the Bay of Bengal. This caused increase in water vapour values $\left(50-70 \mathrm{Kgm}^{-2}\right)$ over the entire Bay of Bengal during 26th and 27th July, 1992. Consistent with Mahajan (1990), particularly high values were found in the southwestern sector of the monsoon depression.

\section{Acknowledgements}

The author wishes to thank Dr. G B Pant, Director, IITM and Dr. E C Barrett, University of Bristol, UK, for providing facilities and showing keen interest in the study. Thanks are also extended to Dr. S S Singh, Head, Forecasting Research Division, for his encouragement and support during the period of study.

\section{References}

Alishouse J C, Snider J B, Vongsathorn J and Ferraro R R 1990 Determination of oceanic total precipitable water from the SSM/I; IEEE transactions of Geoscience and Remote Sensing 28 811-816

Elliott W P and Gaffen D J 1991 On the utility of radiosonde humidity archives for climate studies; Bull. American Met. Soc. 72 1507-1520

Lojou J Y, Bernard R and Eymard L 1994 A simple method for testing brightness from satellite microwave radiometers; J. Atmos. Ocea. Tech. 11 387-400

Mahajan P N 1990 Estimation of vertical distribution of relative humidity using satellite data; Acta Met. Sinica 4 231-238.

Petty G W 1993 SSM/I algorithms for the estimation of column water vapour; Proceedings of shared processing Network DMSP-SSM/I Algorithm Symp. (Montery, CA.)

Schluessel P and Emery W J 1990 Atmospheric water vapour over oceans from SSM/I measurements; Int. J. Remot. Sens. $11753-766$

Tetens O 1930 Uber einige meteorologische begriffe; Z. Geophysics 6 297-309.

Tjemkes S A Stephens G L and Jackson D L 1991 Spaceborne observation of columnar watervapour-SSM/I observations and algorithm; J.Geophys.Res. 96 10941-10954

Wentz F J 1992 Measurement of oceanic wind vector using satellite microwave radiometers; IIE transactions of Geoscience and Remote Sensing 30 960-972 